\title{
ALGUMAS CONSIDERAÇÕES SOBRE O USO DO DIAGNÓSTICO CLASSIFICATÓRIO NAS ABORDAGENS COMPORTAMENTAL, COGNITIVA E SISTÊMICA
}

\author{
Ederaldo José Lopes \\ Renata Ferrarez Fernandes Lopes \\ Gledson Régis Lobato"
}

\begin{abstract}
RESUMO. O objetivo deste trabalho foi avaliar o uso do diagnóstico classificatório nas abordagens comportamental, cognitiva e sistêmica. Dados da literatura mostram que, na primeira, o uso de sistemas classificatórios é restrito e considerado irrelevante para uma análise funcional do comportamento. Na segunda, não há restrições quanto ao uso de sistemas classificatórios, o que a aproxima mais do modelo médico. Na terceira, o diagnóstico é visto como um processo em evolução contínua. Atualmente pode-se concluir que mudanças paradigmáticas no campo da psicologia vêm reformulando as noções de saúde/doença, com reflexos frutíferos para o diagnóstico psicológico.
\end{abstract}

Palavras-chave: abordagens psicológicas; diagnóstico psicológico; doença mental.

\section{SOME CONSIDERATIONS ON THE USE OF THE CLASSIFICATORY DIAGNOSIS IN THE BEHAVIORAL, COGNITIVE AND SYSTEMIC APPROACHES}

\begin{abstract}
The aim of this work was to evaluate the use of classificatory diagnosis in behavioral, cognitive and systemic approaches. Data from literature reveals that in the first approach, the use of classificatory systems is restricted and considered irrelevant for functional analysis of behavior. In the second approach, there are no restrictions as for the use of classificatory systems, which quite resembles the medical model. Finally in the third approach, diagnosis is viewed as a continuous process. Currently, paradigmatic changes in the field of Psychology have been reformulating health/illness concepts, with beneficial reflections in psychological diagnosis.
\end{abstract}

Key words: Psychological approaches; psychological diagnosis; mental disease.

Os sistemas de classificação das doenças datam da época de Hipócrates (460-377 a.C.); contudo, de acordo com Pessotti (1994), foi Pinel quem inaugurou a psiquiatria como uma especialidade médica. Considerando que as enfermidades sempre significaram um desafio ao homem, as tentativas de superá-las dependiam de saber contra o que se estava lutando. Nesse sentido, os sistemas classificatórios significavam um meio plausível para se atingir tal conhecimento.
Na medida em que as ciências da natureza, livres do jugo da Igreja, caminharam rumo ao entendimento científico das doenças, o modelo médico começou a se configurar, buscando entender as patologias, baseando-se em suposições estáveis, racionais e universais. A partir da Idade Moderna, principalmente nos séculos XVIII e XIX, até os dias atuais, a busca pelo entendimento das causas e manifestações das doenças, como também de seu curso esperado, constitui-se em objetivo fundamental, do qual decorre,

\footnotetext{
* Doutor em Psicobiologia pela USP-RP e Pós-Doutor em Filosofia da Mente e Ciências Cognitivas pela Universidade Federal de São Carlos, São Carlos-SP, Prof. Adjunto do Instituto de Psicologia da Universidade Federal de Uberlândia, UberlândiaMG.

\# Doutora em Psicobiologia pela USP-RP, Prof. Adjunto do Instituto de Psicologia da Universidade Federal de Uberlândia, Uberlândia-MG.

II Mestre em Psicologia Aplicada pelo Instituto de Psicologia da Universidade Federal de Uberlândia, Uberlândia-MG.
} 
entre outras coisas, a necessidade da manutenção e aprimoramento dos sistemas classificatórios.

O tratamento de determinada doença, então, é direcionado a uma enfermidade específica cujo diagnóstico também possibilita um espaço de diálogo entre profissionais, um código (Garcia, 1997).

Para Ravazzola (1997), a expansão do modelo médico permitiu que o ato de diagnosticar chegasse até os doentes mentais, o que significava dar um sentido de enfermidade a manifestações tidas como bruxaria ou feitiço. Acompanhando essa herança, a psicologia e a psiquiatria contemporâneas lançam mão dos diagnósticos para conduzir tratamentos, possibilitando intervenções mais focadas nas dificuldades observadas. No entanto, as constantes revisões dos grandes manuais nosológicos são acompanhadas por dificuldades de consenso, sugerindo que a facilidade com que os médicos diagnosticam doenças, a partir de um código bem-estruturado, não é possível ser transposta sem retoques profundos para o campo das doenças mentais.

Um dos problemas centrais dos diagnósticos psiquiátricos é a categorização do doente, o que acaba configurando uma espécie de "leito de Procusto". Sabe-se que as informações adquirem seus sentidos dentro de um contexto, e esse processo de construção de significados é um dos modos pelos quais criamos nossa realidade, a qual muitas vezes é considerada como externa e independente de nós. Vivenciando-a, muitas vezes num grau de concretude inapelável, acabamos por criar eventos que confirmam essas crenças sobre como a vida deveria ser, incorrendo naquilo que se convencionou chamar "profecia autorealizadora“. Em outras palavras, na medida em que se procura entender o sentido que o diagnóstico adquire na prática profissional, pode-se perceber o risco que se corre de transformá-lo num mantenedor de problemas, pois ele pode criar sentidos tautológicos para as experiências de uma pessoa.

Por exemplo, após definir alguém como deprimido, comportamentos, sentimentos, pensamentos posteriores que podem ser eventos naturais da vida passam a adquirir sentidos que comprovam o rótulo recebido. Nesse sentido, para ilustrar, tome-se o caso descrito por Rosenhan (1994), em que oito pessoas mentalmente saudáveis foram internadas em doze

Procusto era um rei da mitologia grega que acreditava ser ele próprio o modelo de perfeição. Assim, seu reino também deveria ser perfeito e a medida da perfeição era seu leito, que foi colocado em praça pública, onde as pessoas se deitavam. Se o súdito fosse menor que a cama, ele era esticado até alcançar o tamanho da cama. Se fosse maior que a cama, o que sobrasse era cortado. clínicas diferentes. Elas usaram pseudônimos e as que trabalhavam na saúde mental disseram ter outras profissões. Eram clínicas em cinco estados das costas Leste e Oeste dos EUA. Após marcar a internação, o paciente apresentava-se queixando-se de vozes, que pareciam ser de uma pessoa do mesmo sexo. O conteúdo das vozes era pouco claro, referindo-se a "vazio", "buraco", "ruído surdo", que denotaria uma entidade nosológica inexistente, "uma psicose existencial". Os sujeitos relataram seu passado de forma inalterada. Depois de internados, deixavam de apresentar sintomas, agindo normalmente, passando grande parte do seu tempo fazendo anotações sobre o hospital. Nenhum dos pseudopacientes foi desmascarado, e quem apontou que não eram doentes mentais foram os internos das instituições, dizendo que eram jornalistas realizando anotações. O tempo das internações variou de sete a cinqüenta e dois dias, com média de dezenove dias. Os diagnósticos foram um de esquizofrenia e os outros de esquizofrenia "em regressão". Quando esses dados foram apresentados, o pessoal de uma clínica-escola não acreditou que pudessem incorrer nos mesmos equívocos. Então, um outro experimento foi elaborado (Rosenhan, 1994) e foi dito às pessoas que trabalhavam nessa clínica que nos três meses seguintes eles seriam visitados por pseudopacientes. Após o período, a clínica se pronunciou afirmando ter 193 instruções sobre pacientes com " 41 considerados por pelo menos um membro da equipe como muito provavelmente simulados, 23 foram considerados por pelo menos um psiquiatra como suspeitos e 19 o foram por um psiquiatra e outro membro da junta" (p.124). Todavia, nenhum pseudopaciente foi admitido nessa clínicaescola durante esse período.

Apesar das críticas, a psicologia clínica tem historicamente se debatido com a necessidade de um diagnóstico nosológico, psiquiátrico e descritivo, e, em algumas abordagens, os psicólogos têm seguido as classificações psiquiátricas, como a do Manual Diagnóstico e Estatístico de Transtornos Mentais DSM IV (American Psychiatric Association, 1994). Todavia, o critério classificatório é tomado, muitas vezes, como um guia compreensivo de um quadro psicopatológico, com a finalidade de se manter uma comunicação entre profissionais, sobretudo entre psicólogos e médicos psiquiatras.

A partir dessas considerações, objetiva-se, neste trabalho, avaliar o emprego do diagnóstico classificatório em psicologia e como diferentes abordagens têm buscado, com ou sem esse referencial, propor formas diagnósticas particulares ou mesmo dispensar esse procedimento. Serão discutidas três 
abordagens psicoterapêuticas: a comportamental (análise funcional), a cognitiva e a sistêmica.

\section{ABORDAGEM COMPORTAMENTAL}

A abordagem comportamental é uma pletora de técnicas e teorias psicológicas que têm os princípios da aprendizagem como o elemento-alvo a ser analisado no surgimento e manutenção das psicopatologias. Essa diversidade de concepções, aliada à introdução dos termos e concepções cognitivos, pode ser rotulada de abordagem comportamental-cognitiva (Abreu \& Guilhardi, 2004; Kerbauy, 2001; Rangé, 2001), ou modificação cognitiva do comportamento (Mahoney, 1995/1997; Meichenbaum, 1993). Embora a cognição tenha se aproximado do comportamento, há distinções entre eles e, por essa razão, são tratados separadamente neste trabalho (Beck \& Alford, 1997/2000; Mahoney, 1995/1997).

A terapia comportamental, historicamente, tem proposto uma forma de intervenção clínica que requer a avaliação precisa do comportamento-alvo e de sua interdependência com outros comportamentos, a especificação da topografia do comportamento, as dimensões e funções do comportamento, a história de reforçamento, a freqüência e ocorrência dos comportamentos desadaptativos. É, pois, das relações funcionais entre os estímulos do ambiente e as respostas da pessoa que se podem planejar as mudanças comportamentais desejadas e, por conseguinte, o processo de resolução dos problemas apresentados por ela. Portanto a abordagem comportamental é empregada no sentido de se entender por que aquele indivíduo, vivendo dentro de certas situações e num dado momento, apresenta aqueles comportamentos e os mantém. Desse modo, o terapeuta comportamental busca descobrir as causas que originaram aqueles comportamentos desadaptativos, assim como os fatores envolvidos na sua manutenção. A investigação dessas causas e dos fatores de manutenção dos comportamentos é feita via método experimental, ou seja, como Torós (2001) explica

na coleta desses dados, deve-se formular hipóteses, controlar mudanças nas variáveis dependentes e independentes, reformular hipóteses e relacionar todas essas variáveis às queixas do indivíduo e, finalmente, a partir dessas hipóteses, deverá ser criada uma metodologia de mudança. A esse processo nós chamamos de Análise Comportamental. (p.95)
O processo de identificação e análise de todas as variáveis que contribuíram para o aparecimento e para a manutenção da resposta desadaptativa, bem como suas conseqüências para o indivíduo e para o meio, ao longo do tempo, chama-se análise funcional (forma de avaliação das variáveis independentes que interferem nas respostas). Constitui-se no aspecto mais difícil da análise comportamental e talvez seja a maior contribuição da abordagem comportamental para o diagnóstico e a terapia (Kerbauy, 2001; Meyer, 2001; Skinner, 1953/1989; Torós, 2001;).

Em função da queixa inicial trazida pelo cliente, 0 terapeuta investiga as causas externas ${ }^{2}$ das quais 0 comportamento é produto e levanta hipóteses ${ }^{3}$ a fim de comprovar, durante a intervenção, a ocorrência e a freqüência das relações contingenciais. Levantadas as hipóteses, o terapeuta ajuda o cliente a discriminar as contingências em operação, testando o seu funcionamento e sua influência no comportamento. Isso permitirá que o terapeuta e o cliente façam a previsão e o controle do comportamento de ambos, não só nas relações estabelecidas pelo cliente, mas na própria relação terapêutica (Delitti, 2001).

Para a terapia comportamental, os fatores ambientais estressores seriam as variáveis independentes que afetariam as variáveis dependentes

\footnotetext{
Skinner (1953/1989) usa o termo "causa" como sendo uma mudança numa variável independente, e "efeito" como sendo uma mudança numa variável dependente. Daí a "relação de causa e efeito" se transforma numa "relação funcional".

3 O uso do termo hipótese faz referência ao modelo hipotético-dedutivo, o que não condiz com a análise do comportamento. É preciso lembrar que, dentro de certos parâmetros, Skinner (1950) se permite usar teoria e, mais tarde (Skinner, 1972/1999, p. 327) diz que "A análise experimental do comportamento é mais que mensuração. Ela é mais que teste de hipóteses. Ela é um ataque empírico sobre as variáveis manipuláveis das quais o comportamento é função." No uso clínico tal qual aparece neste texto, seria mais apropriado falar em hipótese de trabalho, um guia utilizado pelo terapeuta num momento inicial em que o conhecimento da história das contingências de determinado indivíduo ainda é precário. $\mathrm{Na}$ medida em que os dados completam as lacunas dessa história, a hipótese dá lugar aos fatos, permitindo ao terapeuta um planejamento adequado da intervenção clínica. Prossegue Skinner (1969/1984, p. 287): “Uma prática relevante de resolução de problemas consiste em emitir a resposta questionável numa forma tentativa - por exemplo, como uma hipótese .Levantar uma hipótese difere de afirmar um fato na medida em que a evidência é mais escassa e a punição por estar errada mais provável de ocorrer. A resposta emitida é, entretanto, útil, particularmente se registrada, porque pode entrar em outras atividades de resolução de problemas."
} 
(respostas), cujas consequiências constituiriam os fatores mantenedores da psicopatologia.

Do ponto de vista do emprego de categorias nosológicas, como usadas no diagnóstico psiquiátrico, pode-se dizer que seu emprego é irrelevante e inadequado para uma análise do comportamento. Considerando-se que a análise do comportamento tem como pressupostos os princípios da aprendizagem, não há por que considerar princípios subjacentes ao comportamento que possam agir como causadores dos comportamentos "normais" e "anormais". Além disso, ao behaviorismo radical - que embasa a análise funcional - interessa a análise de casos particulares, o que iria de encontro de um sistema classificatório tal como o DSM, já que dois indivíduos classificados como portadores de "transtorno do pânico", por exemplo, teriam idiossincrasias que deveriam ser objeto de análises individuais, ou seja, suas histórias pessoais seriam mais importantes para um diagnóstico "correto", bem como para o tratamento daí decorrente.

As restrições ao uso do DSM não são uma constante dentro da abordagem comportamental. De acordo com Cavalcante e Tourinho (1998), há alguns analistas do comportamento que utilizam esse sistema classificatório, mas eles derivam de uma classe de terapeutas pertencentes ao chamado movimento da modificação do comportamento. Aqueles que são contra o uso de sistemas classificatórios tomam como referência pressupostos do behaviorismo radical (Matos, 1995; Tourinho, 1999).

\section{ABORDAGEM COGNITIVA}

A teoria-terapia cognitiva surgiu há mais de três décadas e um grande número de trabalhos tem atestado sua eficácia em diversos transtornos. As formulações teóricas têm recebido suporte a partir de extrapolações dos neopsicanalistas, bem como dos achados experimentais da psicologia cognitiva (Beck, 1993).

De acordo com Beck e Alford (2000), “ a teoria cognitiva articula a maneira através da qual os processos cognitivos estão envolvidos na psicopatologia e na psicoterapia efetiva (p.21)."' Dessa afirmação decorre que a natureza e a função do processamento da informação (a atribuição de significado) são os elementos fundamentais para se compreender o comportamento mal-adaptativo. Portanto, uma análise em termos de processamento da informação enviesado, produzindo julgamentos viciados e uma tendência concomitante de cometer erros cognitivos, fornece os elementos necessários para uma abordagem psicopatológica baseada nas características específicas dos esquemas que formam os perfis psicológicos (Beck \& Freeman, 1990/1993), cuja manutenção pode se dar em função de um mecanismo de "feed-forward" (alimentação-para-frente) (Mahoney, 1984).

Para a abordagem cognitiva (Beck, 1996; Beck \& Alford, 1997/2000; Beck \& Freeman, 1990/1993; Beck, Rush, Shaw, \& Emery, 1979/1997), a noção de esquemas é central. Essa noção ou conceito foi amplamente usada por Bartlett (1932/1995) nos seus estudos sobre o processo social de construção e reconstrução das memórias. Um esquema cognitivo pode ser conceituado como "o padrão complexo, gravado na estrutura organísmica pela experiência, que combina com as propriedades do objeto de estímulo apresentado ou a idéia apresentada para determinar como o objeto ou a idéia deve ser percebido ou conceitualizado" (Beck, 1964; Beck \& Alford, 1997/2000). Em outras palavras, os esquemas são estruturas organizadoras das informações memorizadas que influenciam a forma pela qual percebemos e respondemos a outras informações, tais como objetos, eventos e pessoas (Pervin \& John, 2001/2004). Assim as estruturas cognitivas esquemáticas determinam a forma pela qual o indivíduo estrutura o mundo, de tal modo que seus afetos, comportamentos e fisiologia são funções de regras (esquemas) construídas ao longo da vida , pressupondo-se, desta forma, que a origem da ação está em um nível consciente, sujeita a processos controlados e automáticos. Não há esquemas cognitivos somente. Para Beck e Freeman (1990/1993), os esquemas podem ser cognitivos (ligados à abstração, interpretação e memória), afetivos (ligados à geração de sentimentos), motivacionais (vontades e desejos), instrumentais (preparação da ação) e de controle (automonitoramento e inibição ou direcionamento das ações).

A noção de esquemas é fundamental para o entendimento do que é patológico dentro da teoria cognitiva. Os esquemas selecionam, organizam e orientam o comportamento, pois sustentam e estabelecem critérios avaliativos da realidade, preparando o indivíduo para um certo tipo de atividade cognitiva a fim de perceber eventos como aditivos e apetitivos (alegria, felicidade), como subtrativos (tristeza, pesar), como ameaçadores (medo, pavor), invasivos (raiva, agressão). Padrões persistentes de interpretação da realidade, inflexibilidade e rigidez de esquemas densos e hiperativos são fatores mantenedores da psicopatologia. 
Com relação aos elementos predisponentes, cabe destacar a visão evolutiva e filogenética sobre a qual se alicerça a terapia cognitiva. Por exemplo, Beck e Freeman (1990/1993) afirmam que a personalidade opera a serviço da adaptação, que nossos padrões de personalidade poderiam derivar de nossa herança filogenética e que nossos traços de personalidade poderiam ser conceituados a partir da manifestação de estruturas subjacentes (esquemas), selecionados a partir da filogenia da espécie humana e da ontogenia dos comportamentos individuais; em outras palavras, o processamento cognitivo e os elementos que dele derivam (esquemas afetivos, motivacionais, de controle, comportamentais) evoluíram como resultado de nossa capacidade de sobreviver e deixar descendentes. Desta forma, a psicopatologia parece fundamentar-se na interação entre fatores genéticos (a diátese) e a interação com o ambiente, ou, dito de outra forma, da interação entre natureza e educação. A psicopatologia resulta da construção de significados mal-adaptativos em relação ao self, ao contexto ambiental (experiência) e ao futuro (metas), que são denominados de tríade cognitiva. Por conseguinte, cada síndrome clínica tem suas características associadas aos elementos da tríade. Por exemplo, na depressão, os três componentes são interpretados de forma negativa. $\mathrm{Na}$ ansiedade, o self é visto como inadequado (deficiente em recursos), o contexto é interpretado enviesadamente como perigoso e o futuro, incerto. Na raiva e nos transtornos paranóides, o selfé visto como sendo maltratado ou objeto de abuso pelos outros, e o mundo é visto como injusto e em oposição aos interesses do indivíduo.

O caráter estrutural de uma crença (esquema) afetando o caráter funcional de um comportamento é indiscutível. A título de exemplo, tome-se o conceito de fusão pensamento-ação (Abramowitz, Whiteside, Lynam, \& Kalsy, 2003), típica do transtorno obsessivo-compulsivo: a crença de que pensar implica aumentar a probabilidade de que algo terrível ocorra consigo ou com o outro, em função da fusão pensamento-ação estabelecida, leva o indivíduo a estabelecer um ritual a fim de evitar que o que foi pensado se concretize. Assim a função do ritual é diminuir a probabilidade de que aquilo que foi pensado se realize, ou seja, esta fusão pensamento-ação, de ordem probabilística ou moral, delega ao ritual um caráter funcional desadaptativo, que, não obstante, aos olhos de quem o executa, é necessário e funcional, a ponto de minimizar ou quase fazer desaparecer sua ansiedade, algo que a seleção natural programou para adaptar a espécie. Desde que a interpretação de um evento real e perigoso favorece estratégias de fuga e esquiva adequadas, essa interpretação se torna desadaptativa e patológica à medida que é inadequada, repetitiva e independente do contexto.

$\mathrm{Na}$ abordagem cognitiva não há nenhuma restrição ao uso de sistemas classificatórios. O uso do sistema DSM dentro dessa abordagem se faz de forma a procurar como os perfis psicológicos se encaixam nas classificações dos transtornos psiquiátricos, a partir dos quais os terapeutas planejam com seus clientes os passos da terapia. Além disso, o diálogo com a psiquiatria se faz pelo fato de essa abordagem encarar os fenômenos psicológicos mais propriamente como fenômenos psicobiológicos, donde o uso de psicofármacos poder ser feito conjuntamente com o tratamento psicoterapêutico (Lotufo Neto \& Araújo, 1995).

\section{ABORDAGEM SISTÊMICA}

A psicologia, desde os seus primórdios, buscou entender o homem principalmente do ponto de vista intrapsíquico. Assim a doença mental acabou sendo considerada como um problema "dentro" da cabeça do sujeito. A partir da década de 1930, a Psiquiatria Clássica incluiu em seus diagnósticos o papel da família na patologia (Nichols \& Schwartz, 1995/1998). Todavia, foi na década de 1950, quando o Projeto Bateson já havia rendido frutos e vários outros teóricos se empenhavam em analisar o aspecto relacional do homem, que se passou a ter uma outra possibilidade de enfoque das doenças mentais. As pesquisas empreendidas nesse período demonstraram que, ampliando-se o foco de análise para a família, ou seja, utilizando-se $\mathrm{o}$ aspecto relacional do homem como fator para entender a doença mental, encontrar-se-iam respostas que não são equacionadas considerando-se apenas o fator intrapsíquico.

Esse movimento de ampliação do foco de análise para a família encontra respaldo na idéia de tratar os fenômenos da vida e, mais especificamente, o ser humano, como possuidores das características de um sistema, ou seja, um conjunto de elementos interligados para formar um todo com características próprias que não são encontradas em nenhum dos elementos isolados (Bertalanffy, 1968/1975). Em sua Teoria Geral dos Sistemas, Bertalanffy (1968/1975) discute a noção de sistemas aplicada a vários campos do conhecimento, afirmando a existência de dois tipos de sistemas: sistemas abertos, que realizam trocas com o meio, e sistemas fechados, que não realizavam trocas com o meio. O homem seria um sistema aberto, donde decorre que a compreensão de seu psiquismo só deve ser feita à luz das considerações das relações 
interpessoais e com o meio no qual ele está inserido, incluindo os aspectos culturais.

Uma das características mais discutidas na Teoria dos Sistemas é a abertura, característica presente, até certo grau, em todos os sistemas. Watzlawick, Beavin e Jackson (1967/1993) apresentam alguns princípios que caracterizam os sistemas abertos. 1) A globalidade, que se refere à interdependência entre as partes de um sistema, isto é, um sistema é um todo (gestalt), que não é a mesma coisa que a soma de suas partes independentes (princípio da não-somatividade). 2) $\mathrm{O}$ princípio da retroação ou circularidade assegura que nas relações interpessoais cada indivíduo influencia e sofre a influência do outro. 3) O princípio da equifinalidade assegura que um mesmo objetivo pode ser atingido a partir de vários meios diferentes; isto significa dizer que os sistemas abertos podem atingir um estado independentemente do que tenha sido programado nos estágios iniciais.

Vindo a conceituar o homem como um sistema aberto, Bertalanffy (1968/1975) estaria libertando as Ciências Humanas do modelo das Ciências Exatas, porquanto as últimas tratariam de sistemas fechados, e a aplicação de tal paradigma às Ciências Humanas acabaria por negligenciar o aspecto mais fundamental do seu objeto, a saber, sua abertura ao ambiente.

Também a Cibernética foi fundamental à noção de sistemas. Rosenblueth, Wiener e Bigelow (1943) publicaram um artigo chamado Conduta, Propósito $e$ Teleologia, no qual, buscando pesquisar sobre máquinas que tivessem o propósito de explicar fenômenos de outras áreas, elaboraram o conceito de retroação (feedback). Quando um desvio ocorre no funcionamento de um sistema, laços de retroação negativa atuam diminuindo a variação, levando-o ao padrão anterior. Emerge aqui, no âmago da ciência clássica, a idéia de circularidade, a possibilidade de auto-regulação do sistema. Dessa forma, a Teoria Geral dos Sistemas e a Cibernética deram respaldo ao conceito de ser humano como ser relacional, possibilitando o surgimento de novas formas de atuação, inclusive da terapia familiar.

Todavia, o entendimento do processo terapêutico ainda se encontrava marcado pela herança clássica. Os terapeutas de família desse período fundamentavam sua prática numa teoria de estabilidade (a Cibernética), considerando-se separados da família. Cabia ao terapeuta, então, observar os padrões relacionais disfuncionais da família e se movimentar para modificá-los (Boscolo, Cecchin, Hoffman \& Penn, 1987/1993).

A partir desse momento, no cenário científico, emerge uma mudança na visão de mundo, delineando um novo contexto que repercutiu de maneira decisiva nas práticas de terapia familiar. Prigogine (1996/1996) questiona a noção de estabilidade, demonstrando, a partir do estudo das "estruturas dissipativas", que o homem não se constitui na estabilidade, mas sim,como um ser "afastado do equilíbrio", que realiza "saltos qualitativos". Morin (1990) questiona a tendência a simplificar os fenômenos, enfatizando o aspecto do pensamento complexo. Maturana, Magro, Graciano e Vaz (2001) salientam o papel do observador, sendo impossível separar esse observador de uma realidade externa e objetiva, realidade que passa a ser compreendida como constituída de acordos intersubjetivos na linguagem. Dessa forma configurouse o "paradigma Si-Cibernético" (Vasconcelos, 1995), no qual os aspectos precípuos da ciência tradicional (simplicidade, estabilidade e objetividade) são ampliados e englobados por princípios de uma ciência contemporânea (complexidade, instabilidade e intersubjetividade). Nesse momento, deixa de fazer sentido a idéia de um terapeuta que, imbuído de técnicas, intervém num sistema estando dele separado.

A descrição desse percurso tem por objetivo fornecer aspectos gerais da trajetória da construção de uma visão sistêmica de homem e suas repercussões no papel do terapeuta, porquanto refletir sobre $o$ diagnóstico nos leva a pensar sobre o nosso papel, despojando-nos do poder de dizer para alguém o seu problema, um convite para se abrir a um ser humano, com suas dores, angústias, alegrias, uma complexidade que não se reduz a rótulos. Essa passagem para o novo paradigma (Vasconcelos, 1995) inclui necessariamente o terapeuta no processo terapêutico, não sendo mais alguém "de fora", mas uma pessoa que observa os fenômenos de uma forma auto-referente. Ademais, o homem visto a partir da ótica sistêmica se flexibiliza, ganhando em complexidade e transpondo visões estáticas que o definiam, o que se aplica ao uso clássico do diagnóstico.

O diagnóstico, ao centrar a pessoa na sua dificuldade, implica uma definição de ser, uma identidade, supondo características próprias da essência do outro (Ravazzola, 1997), as quais se cristalizam no tempo, na medida em que o sujeito aceita o rótulo como constitutivo do seu ser. O modelo médico, derivado das ciências da natureza, freqüentemente olvida o efeito das crenças, dos afetos, dos comportamentos na construção de profecias autorealizáveis (Ravazzola, 1997), desconhecendo o poder da linguagem na construção de realidade. Por outro lado, os teóricos sistêmicos, ao falarem de relação, 
contexto e comunicação, incluíram o observador e resgataram sua responsabilidade no processo terapêutico, aspectos que necessitam ser integrados na noção do diagnosticar (Ravazzola, 1997).

Quanto ao observador, Maturana, Magro, Graciano e Vaz (2001) afirmam que esse cria a realidade que observa através do processo de distinção, cujas diferenças determinam a constituição de domínios de realidade construídos na linguagem. $O$ que $o$ observador distingue é uma unidade. As unidades podem ser simples, quando não as decompomos, ou compostas, quando suas partes podem ser dissociadas. Quanto às unidades compostas, podemos distinguir dois aspectos: a estrutura, que é variável, sendo "componentes e as relações que constituem uma unidade particular" (Maturana, Magro, Graciano, \& Vaz, p. 58). A organização é atribuída por um observador, permitindo categorizar uma unidade. Daqui se pode extrair uma contribuição para a utilização dos diagnósticos. Como já se sabe, as categorias nosológicas são elaboradas baseando-se no desenvolvimento de certas disfunções.

Sinais e sintomas são detectados, um prognóstico é estimado e as intervenções terapêuticas visam bloquear o ciclo esperado para a doença. Esses sinais e sintomas - estrutura, de acordo com Maturana, Magro, Graciano e Vaz (2001) - recebem um nome, um diagnóstico, que se constitui numa organização atribuída por um observador. O que ocorre, muitas vezes, é o esquecimento de que o diagnóstico é uma abstração, não uma realidade externa e concreta. Percebendo-o como abstração, podemos inseri-lo na dinâmica da vida para tratar dos problemas humanos, que são cambiantes. Isso possibilita que o diagnosticar torne-se uma hipótese de trabalho numa situação social (Hercovici, 1997, p.72), dando-nos uma orientação probabilística que, somada a uma relação terapêutica cooperativa, abra novas possibilidades de exploração dos aspectos que condicionam o sofrimento na vida do sujeito que busca ajuda. Como muito bem sinalizou Hercovici (1997, p. 73): "Será uma entidade em evolução, que se utilizará para guiar a prática".

\section{CONCLUSÕES}

Entender o diagnóstico como algo que se insere na complexidade da existência e que só existe no olhar do terapeuta exige de nós uma flexibilidade muitas vezes angustiante, porquanto, frequientemente, na prática profissional, somos desafiados a nos apresentar como pessoas capazes de definir o sofrimento do outro, de predizer o seu curso e de intervir. De outro lado, o cliente, paciente ou pessoa, através de uma realidade construída a partir do modelo médico, muitas vezes procura o rótulo de sua doença, de modo que desconstruir essa realidade requer uma mudança cultural dentro do modelo clássico de ciência, ainda em operação.

$\mathrm{O}$ estudo das três abordagens aqui discutidas levanta pelo menos dois problemas com relação ao diagnóstico: o primeiro diz respeito à visão de psicopatologia que cada uma apresenta e sua dependência, em maior ou menor grau, das relações do indivíduo com seu meio social (ambiente), e o segundo, decorrente do primeiro, diz respeito ao problema central que caracteriza o diagnóstico psicológico baseado em sistemas classificatórios. Ou seja, qualquer sistema classificatório é restrito e estático ao longo do tempo e não abarca as idiossincrasias apresentadas pelas pessoas que, mesmo recebendo o mesmo diagnóstico, não se percebem subjetivamente assim.

Com relação ao primeiro aspecto, nenhuma das abordagens nega veementemente que haja alguma disfuncionalidade no comportamento do indivíduo e que isso leve a algum tipo de sofrimento para o indivíduo. A abordagem comportamental analisa possíveis deficiências nas contingências (relações funcionais entre o organismo e seu ambiente) que originam padrões de comportamento que trazem sofrimento ao indivíduo. Nessa abordagem, a "patologia comportamental" não é considerada uma doença. Isto é, os indivíduos não estão doentes, mas eles não conseguem responder apropriadamente às exigências ambientais, ou porque não aprenderam determinadas respostas ou porque aprenderam respostas maladaptativas. Para resumir, há uma ênfase nas contingências, o que implica dar um papel ao ambiente tão importante quanto o que se dá ao organismo.

A teoria cognitiva também valoriza o ambiente externo como agente causal da psicopatologia. De acordo com Beck e Alford (1997/2000, p. 42), "na terapia cognitiva, as variáveis dentro do ambiente externo e da experiência fenomenológica interna são integradas em uma teoria unificada, coerente para a prática clínica." Embora não desconsidere o papel do ambiente, a abordagem cognitiva enfatiza as cognições irrealistas ou mal-adaptativas como geradoras da psicopatologia e, nesse sentido, pode-se dizer que, sendo uma abordagem mentalista, coloca no indivíduo, mais que no ambiente, a responsabilidade por possíveis mudanças na busca da redução do sofrimento. Não se pode esquecer, todavia, que alguns 
terapeutas trabalham as duas abordagens, a comporamental e a cognitiva de forma conjunta, o que se convencionou chamar de abordagem comportamental-cognitiva. Nesse sentido, as interpretações dadas até aqui para as abordagens em separado precisariam ser revistas, mas isso não é o nosso objetivo aqui.

Finalmente, a abordagem sistêmico-construtivista, como poderíamos chamar essa abordagem após o rumo que demos a este texto, encara a doença mental como "uma perturbação das funções sistêmicas do organismo psicofísico (Bertalanffy, 1968/1975, p. 290). Assim, considerando o homem como um sistema aberto, essa abordagem necessariamente assegura as trocas entre homem e ambiente.

Estritamente falando, sob a óptica das relações homem versus ambiente, a abordagem comportamental se aproxima mais da sistêmica, pois enfatiza o homem (organismo biológico) como um todo e na relação com um contexto fora dele; ou, na linguagem sistêmica, o homem é uma "gestalt" que está em constante troca com outros sistemas que compõem o universo (sistêmica).

Com relação ao segundo aspecto, pode-se dizer que o caráter estático dos sistemas classificatórios não acompanha as vicissitudes da realidade interna que somente o indivíduo percebe. $\mathrm{O}$ modelo tradicional de classificação é uma visão realista que supõe um mundo de "normalidades" e "anormalidades", vistas como pólos antagônicos e não como realidades "inventadas" nas relações sociais e interpessoais e, por conseguinte, dependentes da visão cultural. As três abordagens não negam explícita e veementemente a importância do diagnóstico, mas o relativizam de acordo com a visão do ser humano/realidade e, como conseqüência, da visão de ciência de cada uma.

A aceitação do diagnóstico classificatório pela abordagem cognitiva não significa o abandono da intersubjetividade. Os esquemas representariam a visão de mundo do paciente, mas essa visão seria estática no momento do diagnóstico e se trabalharia para a busca de sua mudança, desde que eles fossem disfuncionais. Isso implica uma visão de normalidade, a qual se reflete, no tratamento, numa maior diretividade por parte do terapeuta.

Quanto à abordagem comportamental, pode-se dizer que, embora alguns terapeutas restrinjam o uso do diagnóstico, eles aceitam que há certas contingências que levam o indivíduo a alguma disfunção. Entretanto, não importa o nome, mas sim, a análise das relações funcionais que levam a uma possível mal-adaptação do indivíduo. $\mathrm{O}$ trabalho terapêutico consiste em estabelecer ou restabelecer cadeias de estímuloresposta que venham a ser recompensadoras para o indivíduo dentro de seu processo adaptativo.

Finalmente, a abordagem sistêmica (por extensão, as abordagens fundamentadas na epistemologia construtivista) assegura que o processo diagnóstico e terapêutico respeite a realidade da pessoa, cuja construção se dá a cada momento, inclusive durante a terapia. Não há uma realidade externa, objetiva, à qual o indivíduo deva se adaptar. Qualquer disfuncionalidade é vista como um disfuncionalidade do(s) sistema(s), que acarretaria algum tipo de desequilíbrio nas relações; não é doença mental propriamente dita. Desse modo, as classificações nosológicas adquirem o caráter de metáforas - formas condensadas de organização de significado -, e a psicopatologia é vista como "uma ciência da significação e como tal inseparável de um discurso narrativo" (Gonçalves, 1998, p. 27).

A despeito do domínio do modelo tradicional de ciência e do modelo médico de saúde/doença, outras visões de mundo e de ciência vêm surgindo e trazendo uma possível "crise paradigmática". Essa crise vem sendo construída historicamente, mas a partir de 1950 ela chegou a tal ponto que a mente e a subjetividade começaram a ganhar mais força, num movimento chamado por alguns autores de "revolução cognitiva" (Baars, 1986; Gardner, 1985/1995; Mahoney, 1995/1997). Entre as evoluções empreendidas a partir dessa "revolução" estão aquelas abordagens que têm como pano de fundo uma epistemologia construtivista (Duran, 1998; Ferreira, 1998; Grandesso, 1998; Mahoney, 1995/1997; Neimeyer, 1995/1997a,b), cuja proposta se assenta em um novo modelo ontológico-epistemológico de mudanças na concepção homem/realidade, em que ambos são entidades incorporadas, inseparáveis e relacionais (Varela, Thompson, \& Rosch, 1991/2003). Daí decorre que o mundo da objetividade passa a ser o mundo da subjetividade e que "o conhecimento é inseparável da existência, e a existência é inseparável do conhecimento" (Gonçalves, 1995/1997). Essa "revolução", entretanto, não gerou um paradigma unificador nas ciências cognitivas, mas estabeleceu possibilidades muito mais ricas de compreensão da mente, engendradas a partir de um ponto de vista interdisciplinar, cujas conseqüências também se estendem ao diagnóstico e ao tratamento psicoterapêutico.

Não obstante, o quadro apresentado neste trabalho, embora incompleto - pois não abrange outras formas de encarar o diagnóstico (p. ex., a psicanalítica), mostra uma questão a ser respondida 
em outra oportunidade: em nome da interdisciplinaridade, decorrente, em parte, desses novos "paradigmas" nas ciências humanas e na psicologia, em especial, como ficam as comunicações dos diagnósticos entre os profissionais das diversas áreas? Talvez a esperança de Mahoney (1995/1997, pp. 51-52) seja a saída para esta e outras indagações: "As distinções entre abordagens cognitivas, comportamentais e afetivas irão cair, em função de um reconhecimento crescente do holismo (totalidade) enquanto um fator a ser destacado em todos os casos de avaliação, diagnóstico e terapia" (grifos nossos).

\section{REFERÊNCIAS}

Abramowitz, J. S., Whiteside, S., Lynam, D., \& Kalsy, S. (2003). Is thought-action fusion specific to obsessivecompulsive disorder?: A mediating role of negative affect. Behaviour Research and Therapy, 41(9), 991-1121.

Abreu, C. N. \& Guilhardi, H. J. (Orgs.). (2004). Terapia comportamental e cognitivo-comportamental: práticas clínicas. São Paulo: Roca.

American Psychiatric Association. (1994.). Diagnostic and Statistical Manual of Mental Disorders (4 $4^{\mathrm{a}} \quad$ ed.). Washington: Author.

Baars, B. J. (1986). The cognitive revolution in psychology. New York: Guilford Press.

Bartlett, F. C. (1995). Remembering: A study in experimental and social psychology. Cambridge: Cambridge University Press. (Original publicado em 1932).

Beck, A. T. (1964). Thinking and depression 2: Theory and therapy. Archives of General Psychiatry, 10, 561-571.

Beck, A. T. (1993). Cognitive therapy: Past, present, and future. Journal of Consulting and Clinical Psychology, 61(2), 194-198.

Beck, A. T. (1996). Beyond belief: A theory of modes, personality, and psychopathology. In P. M. Salkovskis (Ed.), Frontiers of cognitive therapy (pp. 1-25). New York: The Guilford Press.

Beck, A. T. \& Alford, B. A. (2000). O poder integrador da terapia cognitiva. Porto Alegre: Artmed. (Original publicado em 1997).

Beck, A. T. \& Freeman, A. (1993). Terapia cognitiva dos transtornos de personalidade. Porto Alegre: Artes Médicas. (Original publicado em 1990).

Beck, A. T., Rush, A. J., Shaw, B. F., \& Emery, G. (1997). Terapia cognitiva da depressão. Porto Alegre: Artes Médicas. (Original publicado em 1979).

Bertalanffy, L. V. (1975). Teoria Geral dos Sistemas. Petrópolis: Vozes. (Originalmente publicado em 1968).

Boscolo, L., Cecchin, G., Hoffman, L., \& Penn, P. (1993). A terapia familiar sistêmica de Milão. Porto Alegre: Artes Médicas. (Original publicado em 1987).
Cavalcante, S. N. \& Tourinho, E. Z. (1998). Classificação e diagnóstico na clínica: possibilidades de um modelo analítico-comportamental. Psicologia: Teoria e Pesquisa, 14, 139-147.

Delitti, M. (2001). Análise funcional: o comportamento do cliente como foco da análise funcional. Em M. Delitti (Org.). Sobre comportamento e cognição: a prática da análise do comportamento e da terapia cognitivocomportamental (pp. 35-42). Santo André: ESETec.

Duran, A. P. (1998). Construtivismo em psicoterapia: continuidade e ruptura. Cadernos de Psicologia, 4(1), 4148.

Ferreira, R. F. (1998). Construtivismo: um momento de síntese ou uma nova tese? Cadernos de Psicologia, 4(1), 27-39.

Garcia, A. G. (1997). El diagnóstico?: mantiene o disuelve el problema? Sistemas Familiares, 13(2), 69-72.

Gardner, H. (1995). A nova ciência da mente: uma história da revolução cognitiva. São Paulo: EDUSP. (Originalmente publicado em 1985).

Gonçalves, O. F. (1997). Hermenêutica, construtivismo e terapias comportamental-cognitivas: do objeto ao projeto. Em R. A. Neimeyer \& M. J. Mahoney (Orgs.), Construtivismo em psicoterapia (pp.161-189). Porto Alegre: Artes Médicas. (Originalmente publicado em 1995).

Gonçalves, O. F. (1998). Psicoterapia Cognitiva Narrativa: manual de terapia breve. Campinas: Psy.

Grandesso, M. A. (1998). Construtivismo ou construtivismos?: encontros e desencontros entre os diferentes grupos. Cadernos de Psicologia, 4(1), 9-26.

Hercovici, P. (1997). A propósito del diagnóstico. Sistemas Familiares, 13(2), 72- 75.

Kerbauy, R. R. (2001). Contribuição da psicologia comportamental para a psicoterapia. Em M. Delitti (Org.). Sobre comportamento e cognição: a prática da análise do comportamento e da terapia cognitivo-comportamental (pp. 1-7). Santo André: ESETec.

Lotufo Neto, F. \& Araújo, L. A. (1995). Psiquiatria e psicofarmacologia. Em B. Rangé (Org.). Psicoterapia comportamental e cognitiva: pesquisa, prática, aplicações e problemas (pp. 293-300). Campinas: Editorial Psy II.

Mahoney, M. J. (1984). Behaviorism, cognitivism, and human change processes. In M.A. Redá \& M. Mahoney (Eds.), Cognitive psychotherapies: Recent developments in theory, research, and practice. (pp. 3-30). Cambridge: Ballinger.

Mahoney, M. J. (1997). Evolução contínua das ciências cognitivas e psicoterapias. Em R. A. Neimeyer \& M. J. Mahoney (Orgs.) Construtivismo em psicoterapia (pp.38-59). Porto Alegre: Artes Médicas. (Original publicado em 1995).

Matos, M. A. (1995). Behaviorismo metodológico e behaviorismo radical. Em B. Rangé (Org.). Psicoterapia comportamental e cognitiva: pesquisa, prática, aplicações e problemas (pp. 27-34). Campinas: Psy II.

Maturana, H., Magro, C., Graciano, M. \& Vaz, N. (2001). A ontologia da realidade. Belo Horizonte: Editora UFMG. 
Meichenbaum, D. (1993). Changing conceptions of cognitive behavior modification: Retrospect and prospect. Journal of Consulting and Clinical Psychology, 61(2), 202-204.

Meyer, S. B. (2001). O conceito de análise funcional. Em M. Delitti (Org.). Sobre comportamento e cognição: a prática da análise do comportamento e da terapia cognitivocomportamental (pp. 29-34). Santo André: ESETec.

Morin, E. (1990). Introdução ao pensamento complexo. Lisboa: Instituto Piaget.

Neimeyer, R. A. (1997a). Um convite às psicoterapias construtivistas. Em R. A. Neimeyer \& M. J. Mahoney (Orgs.). Construtivismo em psicoterapia (pp.5-11). Porto Alegre: Artes Médicas. (Original publicado em 1995).

Neimeyer, R. A. (1997b). Um convite às psicoterapias construtivistas. Em R.A. Neimeyer \& M. J. Mahoney (Orgs.). Construtivismo em psicoterapia (pp.15-37). Porto Alegre: Artes Médicas. (Original publicado em 1995).

Nichols, M. P. \& Schwartz, R. C. (1998). Terapia familiar: conceitos e métodos. Porto Alegre: Artmed. (Original publicado em 1995).

Pervin, L. A. \& John, O. P. (2004). Personalidade: teoria e pesquisa. Porto Alegre: Artmed. (Original publicado em 2001).

Pessotti, I. (1994). A loucura e as épocas. Rio de Janeiro: Editora 34.

Prigogine, I. (1996). O fim das certezas: tempo, caos e leis da natureza. São Paulo: EdUnesp. (Original publicado em 1996).

Rangé, B. (Org.) (2001). Psicoterapias CognitivoComportamentais: um diálogo com a psiquiatria. Porto Alegre: Artmed.

Ravazzola, M. C. (1997). Acerca del "diagnosticar". Sistemas Familiares, 13(2), 98-101.

Rosenblueth, A., Wiener, N. \& Bigelow, J. (1943). Behavior, teleology and purpose. Philosophy of Science, 10, 18-24.

Rosenhan, D. (1994). A sanidade em um ambiente doentio. Em P. Watzlawick. e cols. A realidade inventada: como sabemos o que cremos saber? (pp. 117-143). Campinas: Ed. Psy II.
Skinner, B. F. (1950). Are theories of learning necessary? Psychological Review, 57, 193-216.

Skinner, B. F. (1984). Contingências de reforço: uma análise teórica. (Coleção: Os Pensadores). São Paulo: Abril Cultural. (Original publicado em 1969).

Skinner, B. F. (1989). Ciência e comportamento humano. São Paulo: Martins Fontes. (Originalmente publicado em 1953).

Skinner, B. F. (1999). Some relations between behavior modification and basic research. Em B. F. Skinner. Cumulative record: Definitive edition. Acton: Copley Publishing Group. (Originalmente publicado em 1972).

Torós, D. (2001). O que é diagnóstico comportamental. Em M. Delitti (Org.). Sobre comportamento e cognição: a prática da análise do comportamento e da terapia cognitivocomportamental (pp. 94-99). Santo André: ESETec.

Tourinho, E. Z. (1999). Estudos conceituais na análise do comportamento. Temas em Psicologia da SBP, 7(3), 213222.

Varela, F. J., Thompson, E. \& Rosch, E. (2003). A mente incorporada: Ciências Cognitivas e experiência humana. Porto Alegre: Artmed. (Originalmente publicado em 1991).

Vasconcelos, M. J. E. (1995). Terapia familiar sistêmica: bases cibernéticas. Campinas: Editorial Psy.

Watzlawick, P., Beavin, J. \& Jackson, D. D. (1993). A pragmática da comunicação humana. São Paulo: Cultrix. (Original publicado em 1967).

Recebido em 16/05/2005 Aceito em 29/01/2006

Endereço para correspondência: Ederaldo José Lopes. Av. Pará, 1720, Bloco 2C 48, "Campus” Umuarama, CEP 38405-320, Uberlândia-MG. E-mail: ederaldol@umuarama.ufu.br 